\title{
3 Research Square

\section{The Importance of pH Adjustment for Preventing Fibrin Glue Dissolution in the Stomach: an in Vitro Study}

\section{Yoshitaka Takegawa}

KM Biologics Co., Ltd

Toshitatsu Takao ( $\square$ t.takao1234@gmail.com )

Kobe University Graduate School of Medicine

Hiroya Sakaguchi

Kobe University Graduate School of Medicine

Tatsuya Nakai

Kobe University Graduate School of Medicine

\section{Kazuhiro Takeo}

Blood Plasma Product Technical Development Section, KM Biologics Co., Ltd

\section{Yoshinori Morita}

Kobe University Graduate School of Medicine

\section{Takashi Toyonaga}

Kobe University Graduate School of Medicine

\section{Yuzo Kodama}

Kobe University Graduate School of Medicine

\section{Research Article}

Keywords: fibrin glue, polyglycolic acid (PGA), importance of $\mathrm{pH}$ adjustment, stomach, in vitro study

Posted Date: October 12th, 2021

DOI: https://doi.org/10.21203/rs.3.rs-957475/v1

License: (c) (1) This work is licensed under a Creative Commons Attribution 4.0 International License. Read Full License 


\section{Abstract}

Background and study aim: Combined use of fibrin glue and polyglycolic acid (PGA) sheets has attracted attention as a preventive measure for complications associated with endoscopic submucosal dissection. However, fibrin glue is a protein that may be dissolved by gastric acid. We evaluated the effect of artificial gastric acid on fibrin clot.

Materials and methods: The dissolution time of three layers of fibrin glue with PGA sheets was measured in five groups ( $\mathrm{pH} 1.2,2.0,4.0,5.5$, and 6.0 with pepsin). Measurements of three samples per group were made. The mean number of the remaining layers at each measurement point was observed for seven days.

Results: The time to complete dissolution of the three layers of fibrin gel in the three samples was 150 minutes at $\mathrm{pH} 1.2,5$ hours at $\mathrm{pH} 2.0,24$ hours at $\mathrm{pH} 4.0$, and 2 days and 6 hours at $\mathrm{pH} 5.5$.

Conclusion: In order to maintain fibrin glue in the stomach for a long period, there was a need to avoid pepsin activation secondary to acidification of gastric juice. The use of strong antacids is recommended.

\section{Introduction}

The use of fibrin glue has been widely investigated in the field of gastrointestinal endoscopy. The treatment method of using fibrin glue and polyglycolic acid (PGA) sheets has recently attracted attention as a preventive method for complications related with gastric endoscopic submucosal dissection (ESD) or gastrointestinal fistula. In fact, some reports suggested the effectiveness of fibrin glue and PGA sheets in fixing ESD-related perforation or gastrointestinal fistula [1-4] and in preventing delayed bleeding in patients taking antithrombotic drugs [5-7]. The use of fibrin glue as a preventive measure for post-ESD stenosis in the vicinity of the cardia of the stomach is under consideration [8]. Fibrin glue is very compatible with gastrointestinal endoscopy because of its ability to be delivered to the target site as a liquid and its high biocompatibility. Although it is expected to be used in a wide range of applications, the adhesion time of fibrin glue to the target site of the PGA sheet varies among cases. In a report by Fukuda et al, this adhesion time ranged from 1 to 32 days [5]. Because fibrin glue mainly comprises plasmaderived proteins, its use in the stomach carries the risk for dissolution by gastric acid; this may be one of the reasons for the variable effect of fibrin glue. Therefore, in this in vitro study, we investigated the effects of the protein-digesting enzyme pepsin and $\mathrm{pH}$ level on fibrin glue.

\section{Materials And Methods}

A PGA sheet measuring $2.3 \mathrm{~cm}$ in diameter (NEOVEIL sheet 0.15, GUNZE LIMITED, Kyoto Japan) was placed on the bottom of a glass vial and fixed using fibrin glue (BOLHEAL ${ }^{\circledR}, \mathrm{KM}$ Biologics Co., Ltd., Kumamoto Japan). Fibrin glue comprises two solutions (i.e., fibrinogen and thrombin); $0.25 \mathrm{~mL}$ of each solution was used to form a 1-mm-thick layer of fibrin glue containing a PGA sheet. This was repeated three times to form a total of three layers per vial. Artificial gastric juice with pepsin was prepared under 
different conditions of $\mathrm{pH} 1.2,2.0,4.0,5.5$, and 6.0; these five groups in total were set up with reference to the activity of pepsin, which peaks at pH 2.0 and drops sharply from pH 4.0 to $\mathrm{pH} 6.0$ (Figure 1) [10]. As a reference, the dissolution rate of fibrin glue by acid without pepsin was also measured at the same $\mathrm{pH}$ levels. Preparation of artificial gastric juice was prepared by adding $1,000 \mathrm{~mL}$ of water to $2.0 \mathrm{~g}$ of sodium chloride and $7.0 \mathrm{~mL}$ of $35 \%$ hydrochloric acid, according to the first solution of the JP Dissolution Test Method. In the pepsin-containing group, porcine gastric mucosa-derived pepsin (2,953 U per mg, BBI Solutions Ltd., Cardiff, United Kingdom) was added at $0.1 \%$. The $\mathrm{pH}$ was adjusted using sodium hydroxide; hydrochloric acid was also used for fine adjustment. Artificial gastric juice $(10 \mathrm{~mL})$ was used for one sample (Figure 2).

A locking mixer with a shaking condition of $8 \mathrm{rpm}$ (RM-80, AS One Co., Ltd., Osaka, Japan) was installed in an incubator (LST-300D, TOKYO RIKAKIKAI CO, LTD., Tokyo, Japan) and set at $37^{\circ} \mathrm{C}$ for the measurements. The mean number of remaining layers was measured every 30 minutes for the first 6 hours, every 6 hours until the third day, and every other day until the seventh day; the measurements were compared in three samples per group. As fibrin dissolved, its degradation products and additives contained in the fibrin glue leached into the artificial gastric juice and raised the $\mathrm{pH}$; therefore, the $\mathrm{pH}$ was adjusted after each measurement. The timing of layer dissolution, which was defined as the release of the PGA sheet into the artificial gastric juice after shaking the vial gently, was recorded (Figure 3).

\section{Results}

All three layers of fibrin in all three samples with pepsin dissolved in 120 minutes in the $\mathrm{pH} 1.2$ group, in 300 minutes in the $\mathrm{pH} 2.0$ group, in 12 hours in the $\mathrm{pH} 4.0$ group, and in 2 days and 6 hours in the $\mathrm{pH} 5.5$ group (Figures 4 and 5). In the pH 6.0 with pepsin group, fibrin was not dissolved at all, even after seven days. In the pepsin-free groups, all three layers of samples disappeared completely after three days in the $\mathrm{pH} 1.2$ group and after four days in the $\mathrm{pH} 2.0$ group; in the $\mathrm{pH} 4.0$ group, fibrin was not dissolved at all even after seven days.

\section{Discussion}

The present study showed that fibrin glue was dissolved by gastric acid, but its dissolution could be significantly prevented by controlling the $\mathrm{pH}$ level. Our results suggested that fibrin glue can be easily dissolved by gastric juice under low $\mathrm{pH}$ conditions. Although the activity of pepsin is the highest at $\mathrm{pH} 2.0$ and is reduced to less than $30 \%$ at pH 1.2 [9], the relatively fast dissolution of fibrin in the $\mathrm{pH} 1.2$ group was likely brought about by cleavage of the fibrin gel fibers by the strong acid itself. Dissolution of fibrin glue was more delayed in $\mathrm{pH} 4.0$ than in $\mathrm{pH} 1.2$ and 2.0, requiring 24 hours for complete dissolution. Although $70 \%$ of pepsin activity remains at $\mathrm{pH} 4.0$ [9], it was likely that the delay in dissolution was secondary to inhibition of protein cleavage by the acid. When the $\mathrm{pH}$ was raised to 5.5 , pepsin activity dropped to below $10 \%$ [9], and fibrin glue dissolution in all samples took two days and six hours. Moreover, at pH 6, the fibrin glue did not dissolve for seven days in any of the layers in all samples. These 
results implied the importance of keep the $\mathrm{pH}$ high to prevent fibrin dissolution in order to both counteract the effect of the acid and inhibit the activity of pepsin.

Vonoprazan is a potassium antagonist that has been shown to maintain an acid-blocking effect that is higher than that of the proton pump inhibitors esomeprazole and rabeprazole in healthy adult men; after a daily dose of $20 \mathrm{mg}$ for seven days, it was found to have a retention rate of $>85 \%$ at $\mathrm{pH} 4$ or higher for 24 hours [10]. The use of vonoprazan may be effective in prolonging the adhesive effect of fibrin glue in the stomach. Although the combination of fibrin glue and PGA sheets has been used for a long time in the surgical field, its basic research and use in clinical practice in the field of gastrointestinal endoscopy had been few. When this strategy used during gastrointestinal endoscopy, it would be necessary to consider issues, such as limited manipulation through the forceps hole and the abundant amount of mucus and digestive juices in the operative field, compared with that in the surgical field.

In previous basic experiments, PGA sheets exposed to highly viscous liquids, such as saliva and gastric mucus, was proven to prevent the adhesion of fibrin glue $[11,12]$. To solve this problem, we developed and showed the usefulness of a delivery system for PGA sheets in the gastrointestinal tract through animal experiments and excised pig stomach [12-14]. Based on this present study, we propose the use of a strong antacid agent to extend the effectiveness of fibrin glue in the gastrointestinal tract. Although accumulation of clinical experience is important, we believe that this additional basic study would strengthen the value of this technique in dealing with complications of gastrointestinal endoscopic procedures.

\section{Limitations}

The in vitro design of study was less ideal for observing fibrin dissolution, compared with that of the actual environment in the stomach for two reasons. First, the constant immersion in artificial gastric acid and continuous shaking of fibrin gel resulted in uninterrupted exposure to acid and pepsin. Second, the absence of viscous components, such as mucin, in the artificial gastric acid made the fibrin gel highly permeable. Fukuda et al reported that PGA sheets fixed with fibrin glue remained in the stomach for up to 32 days [5]; therefore, the results of the present study cannot be applied to clinical practice in the time period. Care must be taken to not overestimate gastric acid dissolution of the fibrin glue.

\section{Conclusions}

Keeping a near neutral $\mathrm{pH}$ in the stomach was important to prevent gastric acid dissolution of fibrin glue. Selection of a strong antacid may be effective in prolonging the duration of fibrin glue retention in the stomach.

\section{Declarations}

Acknowledgements 
Not applicable.

\section{Funding}

Not applicable.

\section{Author contributions}

YT, T Takao: conception and design of the study, literature research and writing of the manuscript. HS, $\mathrm{TN}$ : assisted in the design of the study and revision of the manuscript. YT, KT: derived the models and analyzed the data. YT: performed the measurements. KT: assisted with the measurements. YM, T Toyonaga, YK: involved in planning and supervised the work. The author(s) read and approved the final manuscript.

\section{Competing interests}

Mr. Takegawa and Mr. Takeo are employees of KM Biologics Co., Ltd. and fibrin glue (BOLHEAL $®)$ used in this article is manufactured by KM Biologics Co., Ltd. Dr. Takao, Dr. Sakaguchi, Dr. Nakai, Dr. Morita, Dr. Toyonaga, and Dr. Kodama have no conflict of interest.

\section{Data availability}

The datasets used and/or analysed during the current study are available from the corresponding author on reasonable request.

\section{References}

1. Ono, H., Takizawa, K., Kakushima, N., Tanaka, M. \& Kawata, N. Application of polyglycolic acid sheets for delayed perforation after endoscopic submucosal dissection of early gastric cancer. Endoscopy 47 Suppl 1 UCTN, E18-E19 (2015).

2. Takimoto, K. \& Hagiwara, A. Filling and shielding for postoperative gastric perforations of endoscopic submucosal dissection using polyglycolic acid sheets and fibrin glue. Endosc. Int. Open 4, E661-E664 (2016 Jun).

3. Kawabata, H., et al. Endoscopic closure of an anastomo-cutaneous fistula: filling and shielding using polyglycolic acid sheets and fibrin glue with easily deliverable technique. Endosc. Int. Open 6, E994E997 (2018 Aug).

4. Nakano, Y., et al. Endoscopic plombage with polyglycolic acid sheets and fibrin glue for gastrointestinal fistulas. Surg. Endosc. 33, 1795-1801 (2019 Jun).

5. Fukuda, H. et al. Polyglycolic acid felt sealing method for prevention of bleeding related to endoscopic submucosal dissection in patients taking antithrombotic agents. Gastroenterol. Res. Pract. 2016, 1457357 (2016). 
6. Kawata, N. et al. Efficacy of polyglycolic acid sheets and fibrin glue for prevention of bleeding after gastric endoscopic submucosal dissection in patients under continued antithrombotic agents. Gastric Cancer 21, 696-702 (2018).

7. Kataoka, Y. et al. Endoscopic tissue shielding to prevent bleeding after endoscopic submucosal dissection: a prospective multicenter randomized controlled trial. Endoscopy 51, 619-627 (2019 Jul).

8. Nonaka, S., Oda, I., Abe, S., et al. The management of gastrointestinal stenosis after wide-range ESD for early gastric cancer. Gastroenterol. Endosc. 25, 721-728. [in Japanese] (2013)

9. Piper, D. W. \& Fenton, B. H. pH stability and activity curves of pepsin with special reference to their clinical importance. Gut 6, 506-508 (1965 Oct).

10. Sakurai, Y., et al. Acid-inhibitory effects of vonoprazan $20 \mathrm{mg}$ compared with esomeprazole $20 \mathrm{mg}$ or rabeprazole $10 \mathrm{mg}$ in healthy adult male subjects - a randomised open-label cross-over study. Aliment. Pharmacol. Ther. 42, 719-730 (2015 Sep).

11. Takegawa, Y., Takao, T. \& Ono, H. Fundamental examination into the use of fibrin glue and polyglycolic acid sheets as a method for covering post-ESD ulcers. Gastroenterol. Endosc. 57, 11501157 [in Japanese] (2015)

12. Takao, T., et al. Tissue shielding with polyglycolic acid sheets and fibrin glue on ulcers induced by endoscopic submucosal dissection in a porcine model. Endosc. Int. Open 3, E146-E151 (Apr 2015).

13. Takao, T., et al. A novel and effective delivery method for polyglycolic acid sheets to post-endoscopic submucosal dissection ulcers. Endoscopy 49, 359-364 (2017).

14. Sakaguchi, H., et al. Efficacy of the envelope method in applying polyglycolic acid sheets to postendoscopic submucosal dissection ulcers in living pigs. Clin. Endosc. 54, 64-72 (2021).

\section{Figures}




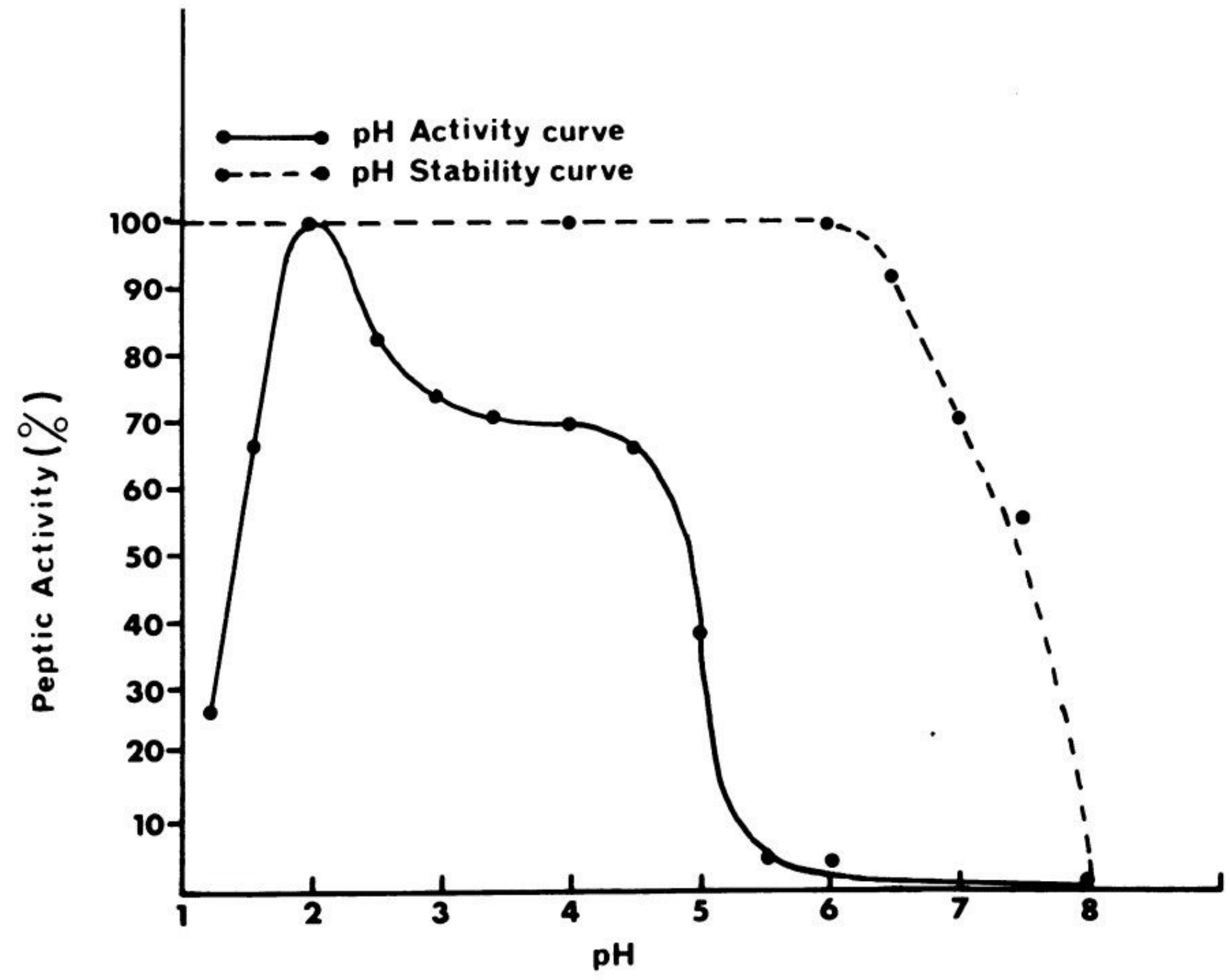

Figure 1

The $\mathrm{pH}$ stability and $\mathrm{pH}$ activity of pepsin. Quoted from Piper DW, Fenton $\mathrm{BH}$. pH stability and activity curves of pepsin with special reference to their clinical importance. 


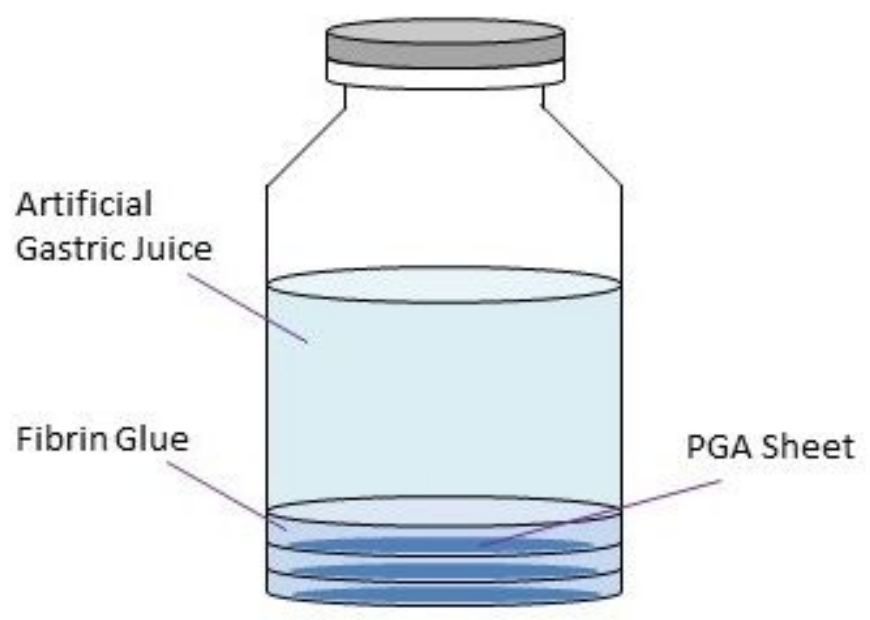

\section{Figure 2}

Samples used in this experiment. Three layers of 1-mm fibrin gel and polyglycolic acid sheet are made in the vial (thickness of $3 \mathrm{~mm}$ in total). A sample for measurement is prepared by adding $10 \mathrm{~mL}$ of the artificial gastric juice.
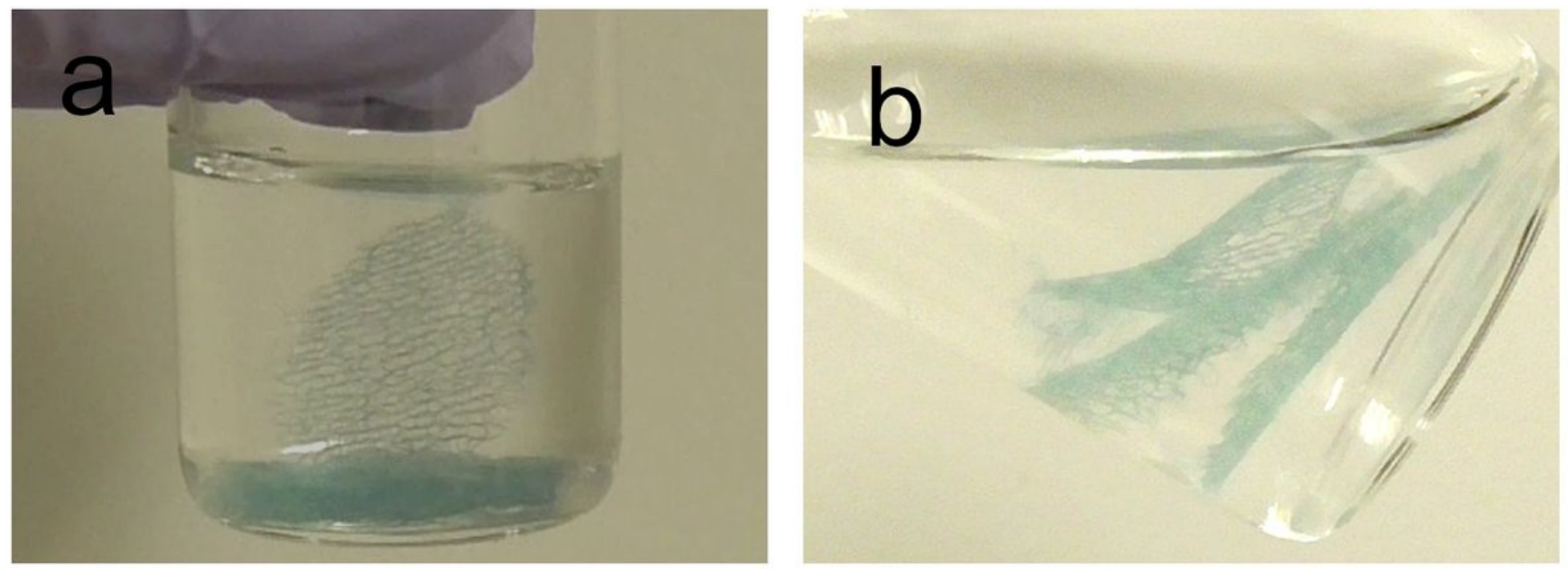

\section{Figure 3}

a) The first layer is dissolved. The first PGA sheet is released into the artificial gastric juice during slow shaking. b) All three layers have dissolved, and three PGA sheets are floating in the artificial gastric juice. PGA, polyglycolic acid sheet 
Number of layers left

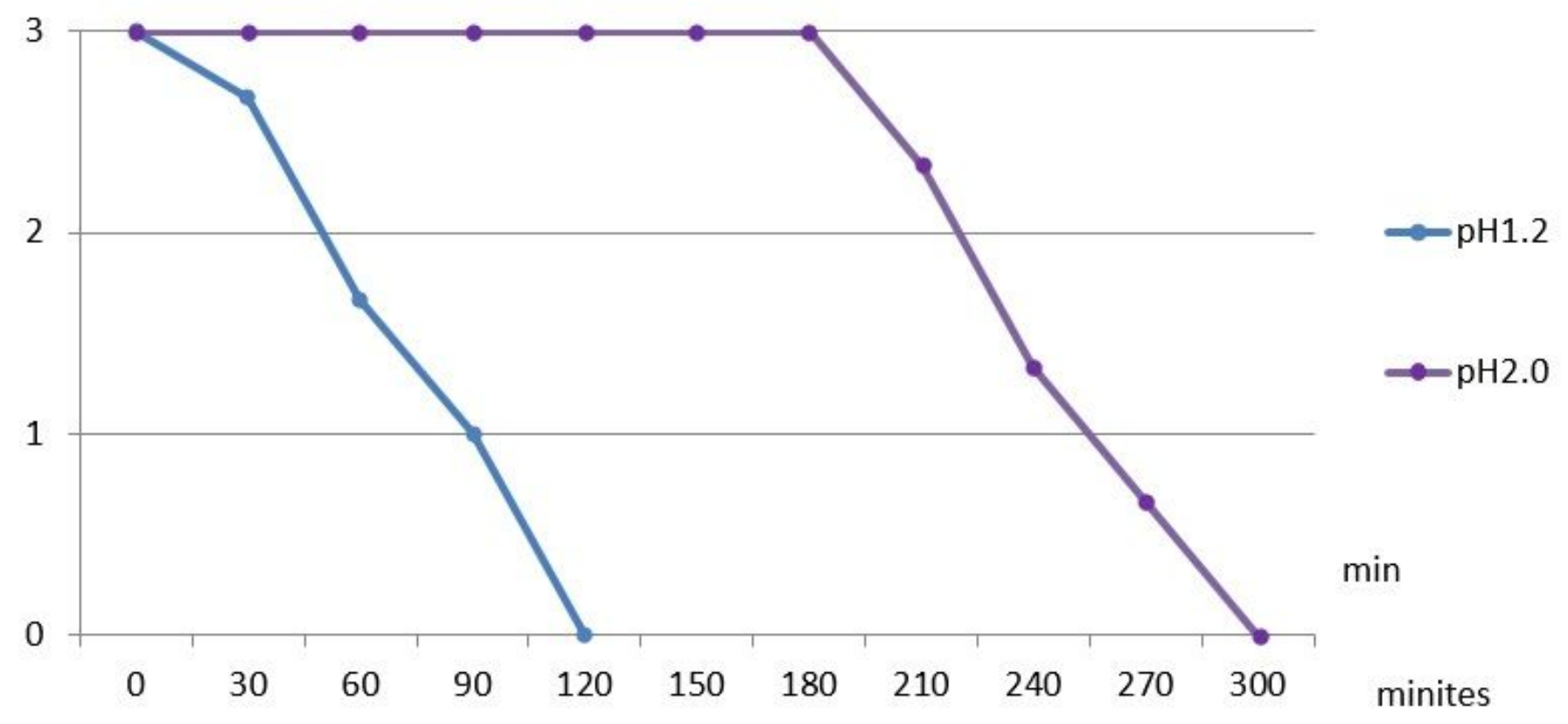

Figure 4

Change in the mean number of the remaining layers in the $\mathrm{pH} 1.2$ and $\mathrm{pH} 2.0$ with pepsin groups over time $(\mathrm{N}=3)$

Number of layers left

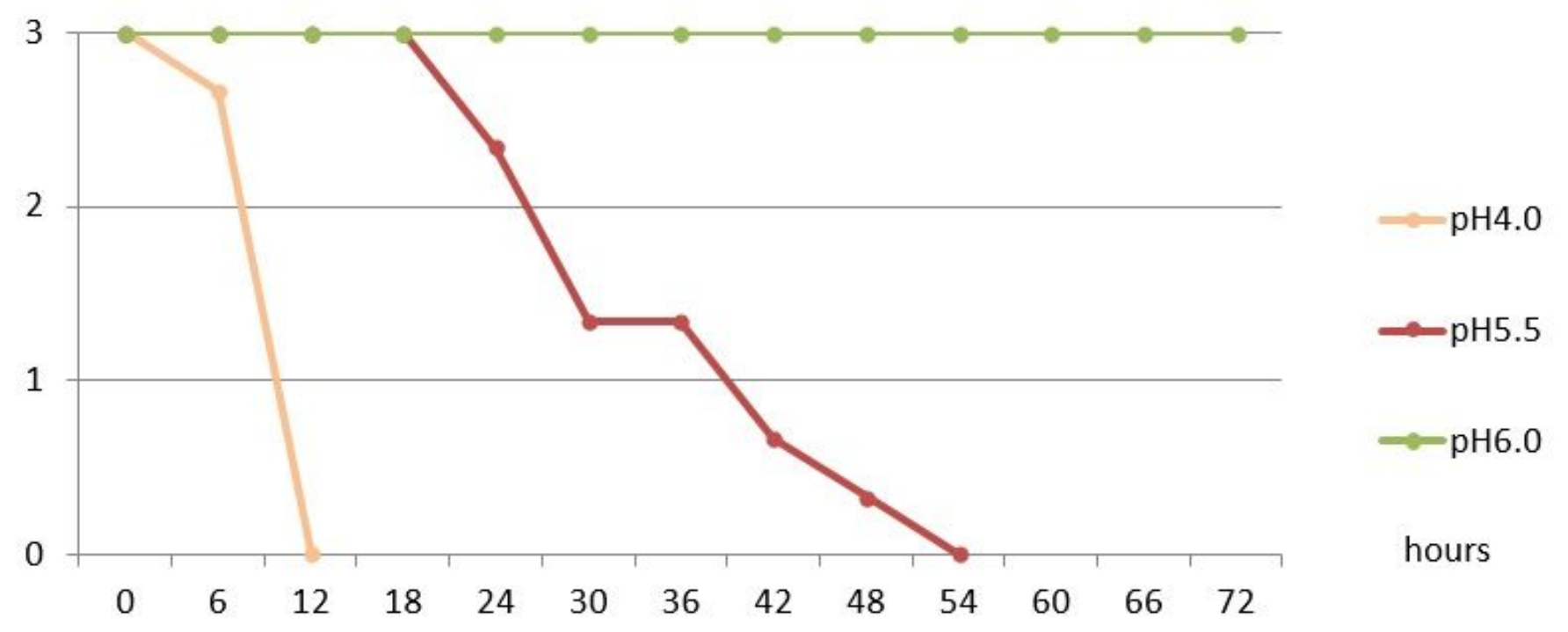

Figure 5 
Change in the mean number of the remaining layers in the $\mathrm{pH} 4.0, \mathrm{pH} 5.5$ and $\mathrm{pH} 6.0$ with pepsin groups over time $(\mathrm{N}=3)$ 